\title{
EFEITO DA REVEGETAÇÃO E DA ADUBAÇÃO DE ÁREA DEGRADADA NA FERTILIDADE DO SOLO E NAS CARACTERÍSTICAS DA PALHADA ${ }^{1}$
}

\author{
NERILDE FAVARETTO², ANÍBAL DE MORAES ${ }^{3}$, ANTÔNIO CARLOS VARGA MOTTA ${ }^{2}$ \\ EBEATRIZMONTE SERRAT PREVEDELLO ${ }^{3}$
}

\begin{abstract}
RESUMO - Este trabalho foi realizado em área degradada pela mineração do xisto com o objetivo de analisar a fertilidade do solo e as características da palhada após a revegetação com espécies forrageiras submetidas a diferentes adubações. O experimento foi conduzido durante 12 meses, no município de São Mateus do Sul, PR, e o delineamento foi de blocos ao acaso com parcelas subdivididas, envolvendo três parcelas referentes às adubações e três subparcelas com as forrageiras. As adubações utilizadas foram: I - adubação mineral com permanência da parte aérea; II - adubação mineral e orgânica com exportação da parte aérea; III - adubação mineral com exportação da parte aérea. As forrageiras constituíram diferentes sistemas da seguinte forma: Sistemas I e II - gramíneas e leguminosas perenes de inverno e verão; Sistema III - gramíneas e leguminosas anuais de inverno e verão. As características químicas do solo foram determinadas nas profundidades de 0-3 e de 3-9 cm. Avaliou-se também a cobertura do solo, o peso da matéria seca residual, a concentração de $\mathrm{C}$ e $\mathrm{N}$ e a quantidade desses elementos sobre o solo. Os tratamentos propiciaram alterações nas propriedades químicas do solo, principalmente na camada de $0-3 \mathrm{~cm}$ e, de modo geral, melhores resultados foram obtidos com adubação orgânica. Considerando o teor de matéria orgânica como o principal fator no processo de recuperação, verificou-se que as espécies perenes foram mais adequadas, no entanto, todas as forrageiras apresentaram alta porcentagem de cobertura do solo.
\end{abstract}

Termos para indexação: solo degradado, recuperação, adubação, forrageira.

\section{EFFECT OF REVEGETATION AND OF FERTILIZATION OF DEGRADED AREA ON SOIL FERTILITY AND ON CHARACTERISTICS OF STRAW MULCH}

\begin{abstract}
This work was carried out on a soil degraded by oil shale mining in São Mateus do Sul, PR, Brazil, to determine the soil fertility and the characteristics of straw mulch after revegetation with forage species submitted to different fertilizations. The experimental design was setup in randomized blocks with split plots, being three plots concerning fertilizations and three subplots with forage species. The fertilizations used were: I - mineral fertilizer with aerial part left over; II - mineral and organic fertilizer with aerial part excluded; III - mineral fertilizer with aerial part excluded. The forages established different systems: Systems I and II - perennial grasses and legumes species of winter and summer; System III - annual grasses and legumes species of winter and summer. The soil chemical properties were determined in the 0-3 and 3-9 cm depths. Percentage of soil covered, weight of residual dry matter, $\mathrm{C}$ and $\mathrm{N}$ concentrations and the amount of these nutrients were also analyzed. The treatments changed the chemical properties of the soil, mainly in $0-3 \mathrm{~cm}$ depth, and in general, better results were obtained with organic fertilization. Considering that the content of organic matter is the main factor on reclamation process, the perennial species were more adequate, however, all forage systems shown high percentage of soil covered.
\end{abstract}

Index terms: degraded soil, reclamation, fertilization, forage.

\footnotetext{
${ }^{1}$ Aceito para publicação em 25 de março de 1999. Extraído da Dissertação de Mestrado do primeiro autor, apresentada à Universidade Federal do Paraná (UFPR).

${ }^{2}$ Eng. Agrôn., M.Sc., Dep. de Solos, Universidade Federal do Paraná (UFPR), Rua dos Funcionários, 1540, Juveve, Caixa Postal 2959, CEP 80035-050 Curitiba, PR. E-mail: nerilde@purdue.edu

${ }^{3}$ Eng. Agrôn., Dr., Dep. de Fitotecnia e Fitossanitarismo, UFPR. E-mail: anibalm@agrarias.ufpr.br
}

\section{INTRODUÇÃO}

A mineração do xisto (folhelho pirobetuminoso) para obtenção de óleo consiste na remoção da camada vegetal e do solo, submetendo a rocha ao processo de retortagem. Na recomposição topográfica, todo o xisto retortado juntamente com outros rejeitos e 
resíduos são depositados nas cavas da mina, obedecendo critérios de disposição a fim de garantir a qualidade da água e da revegetação. O restabelecimento do perfil é efetuado pela disposição de uma camada de argila (mistura de horizontes) com aproximadamente $1,20 \mathrm{~m}$, seguida por $0,5 \mathrm{~m}$ de solo superficial (Terabe, 1992). Esse processo resulta uma intensa alteração do ambiente, sendo imprescindível a recuperação dessa área.

As culturas forrageiras, gramíneas e leguminosas, em função de suas características, têm sido utilizadas em programas de recuperação de áreas degradadas. Segundo Fageria et al. (1991), os sistemas forrageiros, além de fornecer alimentos aos animais, contribuem na renovação da matéria orgânica, previnem a erosão, melhoram a cobertura e restauram a fertilidade do solo. Medeiros et al. (1987) e Testa et al. (1992) constataram o efeito de diferentes sucessões de culturas nas propriedades químicas em solo degradado.

Áreas mineradas são normalmente difíceis de serem vegetadas, em função da fertilidade inadequa$\mathrm{da}$, excesso de acidez, alcalinidade ou salinidade, erosão e outros, sendo necessário efetuar algumas técnicas, incluindo subsolagem, calagem, fertilização mineral e orgânica, bem como utilização de mulching (Troeh et al., 1980). O efeito recuperador da adubação mineral e orgânica nas características químicas do solo em área degradada foi observado por Lucchesi (1988), Melo (1994) e Motta Neto (1995). A permanência do material vegetal sobre o solo tem proporcionado melhores níveis de fertilidade, conforme Sidiras \& Pavan (1985), Havlin et al. (1990), Bhat et al. (1991), Testa et al. (1992) e Christensen et al. (1994).

O objetivo deste trabalho foi avaliar os efeitos de adubações e de espécies forrageiras na fertilidade do solo e nas características da palhada em área degradada pela mineração do xisto.

\section{MATERIAL E MÉTODOS}

O experimento foi conduzido durante 12 meses no município de São Mateus do Sul, PR, em área reconstituída após a mineração do xisto. O delineamento foi o de blocos ao acaso, com parcelas subdivididas envolvendo três parcelas referentes às adubações e três subparcelas com as forrageiras, totalizando 36 unidades experimentais. As adubações consistiam de: I - adubação mineral com permanência da parte aérea (MIN+PA); II - adubação mineral e orgânica com exportação da parte aérea (MIN+ORG-PA); III - adubação mineral com exportação da parte aérea (MIN-PA). As forrageiras foram: Sistema I - gramíneas e leguminosas perenes (pensacola, trevo-branco, trevo-vermelho e cornichão); Sistema II - gramíneas e leguminosas perenes (hemártria, trevo-branco, trevo-vermelho e cornichão); Sistema III - gramíneas e leguminosas anuais (azevém, ervilhaca-peluda e trevo-vesiculoso, no inverno; sorgo e crotalária no verão).

A área recebeu $3.000 \mathrm{~kg} \mathrm{ha}^{-1}$ de calcário (calxisto com $40 \%$ PRNT); tanto o corretivo como os adubos foram distribuídos a lanço, sem incorporação. A quantidade de fertilizante mineral aplicado foi de $44 \mathrm{~kg} \mathrm{ha}^{-1}$ de $\mathrm{N}$, $160 \mathrm{~kg} \mathrm{ha}^{-1}$ de $\mathrm{P}_{2} \mathrm{O}_{5}$ e $150 \mathrm{~kg} \mathrm{ha}^{-1}$ de $\mathrm{K}_{2} \mathrm{O}$, na forma de uréia, superfosfato triplo e simples e cloreto de potássio, respectivamente, metade no plantio das forrageiras de inverno e o restante no plantio das forrageiras de verão. As parcelas com adubo orgânico receberam $13.160 \mathrm{~kg} \mathrm{ha}^{-1}$ por ano (matéria seca) de esterco bovino $(1,9 \% \mathrm{~N}$; $0,5 \% \mathrm{P} ; 1,4 \% \mathrm{~K} ; 1,0 \% \mathrm{Ca}$ e $0,5 \% \mathrm{Mg}$ na matéria seca) que, assim como o fertilizante mineral, foi distribuído a lanço superficialmente, no plantio das forrageiras de inverno e verão. Além do $\mathrm{N}$ aplicado no plantio, efetuaramse adubações de cobertura ( $80 \mathrm{~kg} \mathrm{ha}^{-1}$ de uréia), distribuídas durante o ano de cultivo.

O estabelecimento das forrageiras, exceto das gramíneas perenes de verão que já estavam estabelecidas, foi feito através de semeadura a lanço, sem revolvimento do solo. O plantio das forrageiras perenes e anuais de inverno ocorreu em maio de 93 , e as anuais de verão, em dezembro de 94 . No plantio das anuais de verão foram abertos sulcos, com espaçamento de $50 \mathrm{~cm}$, onde consorciou-se crotalária e sorgo em linhas alternadas.

As amostras de solo foram estratificadas em 0-3 e 3-9 cm, compostas por 20 subamostras em cada subparcela, coletadas no início (maio/94) e no final das atividades (maio/95). O solo, coletado nas diferentes profundidades, foi caracterizado quanto ao $\mathrm{pH}_{\mathrm{CaCl}_{2}} 0,01 \mathrm{M}$; $\mathrm{P}$ e K, pelo método de Mehlich; $\mathrm{Ca}, \mathrm{Mg}$ e $\mathrm{Al}$, extraídos com $\mathrm{KCl} 1 \mathrm{~N}$; $\mathrm{H}+\mathrm{Al}$, determinado pela solução-tampão SMP; C orgânico e N total, pelos métodos Walkley-Black e Kjeldahl, respectivamente (Pavan et al., 1992; Hildebrand, 1977).

O resíduo vegetal morto sobre o solo (palhada) foi caracterizado quanto à porcentagem de cobertura, matéria seca, teor e quantidade de $\mathrm{C}$ e N. A cobertura do solo foi determinada pelo BOTANAL, sistema de programação descrito por Costa \& Gardner (1984), e as avaliações foram efetuadas antes do corte das forrageiras, em 10/94, 
12/94, 1/95 e 3/95. A matéria seca residual foi determinada após a secagem em estufa a $60^{\circ} \mathrm{C}$ das amostras de palhada compostas por três subamostras coletadas em cada parcela antes do corte das forrageiras na estação de inverno e verão, em 10/94 e 2/95, utilizando-se um quadrado de $0,33 \times 0,33 \mathrm{~m}$. Para análise química de $\mathrm{C}$ e N, utilizaram-se as mesmas amostras. Os teores de $\mathrm{C}$ e $\mathrm{N}$ foram determinados nas duas coletas, segundo os métodos Walkley-Black (Tedesco et al., 1985) e Kjeldahl (Hildebrand, 1977), respectivamente. As quantidades de $\mathrm{C}$ e $\mathrm{N}$ sobre o solo na forma de palhada foram obtidas pela multiplicação dos teores desses nutrientes com a matéria seca residual em suas respectivas coletas.

Por meio da análise de variância para o modelo de parcelas subdivididas e comparação de médias pelo teste de Tukey a $5 \%$ de probabilidade, o efeito de espécies forrageiras e adubações foi avaliado nas diferentes épocas de amostragem e profundidades.

\section{RESULTADOS E DISCUSSÃO}

\section{Caracterização química do solo}

A caracterização química do solo constitui-se de duas etapas. A primeira envolve uma discussão geral dos tratamentos em relação aos parâmetros de acidez e aos macronutrientes, com o objetivo de destacar as diferenças entre as épocas de amostragem e profundidades. Na segunda são apresentados e discutidos individualmente os resultados de cada macronutriente, referentes à coleta final do experimento, nas duas profundidades, com o objetivo de caracterizar o efeito dos tratamentos.

Os resultados obtidos (Tabela 1) mostram uma melhoria nas propriedades químicas do solo entre a coleta inicial e final do experimento, principalmente na camada de 0-3 cm. Com relação aos parâmetros de acidez ( $\mathrm{pH}_{\mathrm{CaCl}_{2}}$, $\mathrm{Al}$ e $\left.\mathrm{H}+\mathrm{Al}\right)$, observa-se o efeito superficial do calcário aplicado em cobertura. Santos et al. (1995), após três anos de cultivo em sistema de plantio direto com calcário aplicado na superfície, verificaram que o $\mathrm{pH}$ inicial de 5,5 aumentou para 5,8 na camada de $0-5 \mathrm{~cm}$. Os maiores valores de $\mathrm{pH}$ e menores teores de Al obtidos na camada superficial foram também observados por Klepker \& Anghinoni (1995) em sistema sem preparo do solo, caracterizando um gradiente do $\mathrm{pH}$ e Al com a profundidade.

$\mathrm{O} \mathrm{pH}_{\mathrm{CaCl}_{2}}, \mathrm{Al}$, e $\mathrm{H}+\mathrm{Al}$ não foram alterados entre os tratamentos, em nenhuma das épocas e profundi- dades amostradas. Apesar de os tratamentos apresentarem diferentes teores de $C$ orgânico, não se constatou o efeito da matéria orgânica na acidez do solo.

O uso de calcário e adubos (mineral e orgânico) em cobertura, bem como a reciclagem de nutrientes, propiciaram alterações nos teores de $\mathrm{Ca}, \mathrm{Mg}, \mathrm{K}$ e $\mathrm{P}$, principalmente na camada superficial $(0-3 \mathrm{~cm})$. Observa-se redução dos valores em todos os nutrientes analisados, com a profundidade de amostragem nas duas épocas de coleta indicando redução na fertilidade do solo, em função da profundidade. Esse comportamento é esperado onde não ocorre o revolvimento do solo, como em sistemas de plantio direto, florestais e pastagens, o que está de acordo com os resultados obtidos por Sidiras \& Pavan (1985), Klepker \& Anghinoni (1995) e Santos et al. (1995).

Com relação ao teor médio de $\mathrm{C}$ orgânico (Tabela 1), observa-se que após um ano de experimentação aumentou de 2,65 para $3,24 \%$ na profundidade de $0-3 \mathrm{~cm}$, e de 1,37 para $1,46 \%$ na camada de 3-9 cm, caracterizando um acréscimo de 0,59 e 0,09 unidades percentuais, respectivamente. É interessante salientar que o teor inicial de $\mathrm{C}$ orgânico desta área experimental no ano de 1986 , determinado por Lucchesi (1988), representava $0,5 \%$ na profundidade de 0-15 cm. Motta Neto (1995), nessa mesma área experimental, obteve como média geral do teor de C orgânico, no ano de 1993, o equivalente a 2,42 e $1,28 \%$, respectivamente, na profundidade de $0-3$ e $3-9 \mathrm{~cm}$. Tais resultados evidenciam que a recuperação da matéria orgânica do solo é um processo lento, contínuo, e dependente do sistema de cultivo.

A seguir, será discutido o efeito dos tratamentos sobre os teores de $\mathrm{K}, \mathrm{Ca}, \mathrm{Mg}, \mathrm{C}$ orgânico, $\mathrm{N}$ total, relação $\mathrm{C} / \mathrm{N}$ e $\mathrm{CTC}$ pH 7 do solo na profundidade de $0-3$ e $3-9 \mathrm{~cm}$ referente à coleta final do experimento (maio/95).

As concentrações de $\mathrm{K}$ na profundidade de 0-3 cm (Fig. 1), com exceção do Sistema I, foram significativamente superiores nas parcelas onde a parte aérea permaneceu sobre a superfície, mostrando a contribuição da reciclagem do $\mathrm{K}$ através dessas espécies. Motta Neto (1995) também observou maiores teores de $\mathrm{K}$ no tratamento com adubação mineral e permanência da parte aérea em solo cultivado com espécies forrageiras. 
O tratamento com adubação orgânica não superou a contribuição da parte aérea, apesar de existir um saldo positivo entre adição e extração de K nesse tratamento, caracterizando a maior eficiência da planta em relação ao adubo orgânico. No tratamento com permanência da parte aérea, as espécies forrageiras dos Sistemas II e III apresentaram maiores teores de $\mathrm{K}$ no solo; isso ocorreu devido à maior extração, e, conseqüentemente, maior retorno de $\mathrm{K}$ ao solo através dessas culturas. Dados da produção de matéria seca e da extração de nutrientes relacionados a este experimento encontram-se em Favaretto et al. (2000). Os resultados obtidos por Testa et al. (1992) mostraram que as sucessões de culturas afetaram os teores de $\mathrm{K}$ do solo na mesma proporção que a produção de biomassa.

$\mathrm{O}$ comportamento do $\mathrm{K}$ foi semelhante nas duas profundidades, o que indica uma distribuição no perfil provavelmente determinada pela mobilidade desse elemento e pela contribuição do sistema radicular.

Com relação aos teores de $\mathrm{Ca}$ (Fig. 2) e $\mathrm{Mg}$ (Fig. 3) na profundidade de $0-3 \mathrm{~cm}$, observam-se os melhores resultados nas parcelas com adubação orgânica; no entanto, o teor de $\mathrm{Mg}$ do solo não apresentou interação com as espécies forrageiras. As melhores médias nos teores de $\mathrm{Ca}$ e $\mathrm{Mg}$ na adubação orgânica indicam que o esterco bovino compensou as perdas provenientes da exportação da parte aérea, em função da menor absorção desses nutrientes pelas plantas, em comparações com o K. A média geral da extração de $\mathrm{Ca}, \mathrm{Mg}$ e $\mathrm{K}$ foi 34,23 e
$147 \mathrm{~kg} \mathrm{ha}^{-1}$, enquanto a adição desses nutrientes através do esterco foi de 153,78 e $189 \mathrm{~kg} \mathrm{ha}^{-1}$, respectivamente. Nessa mesma área experimental, Lucchesi (1988) não constatou o efeito da adubação orgânica nos teores de $\mathrm{Ca}$ e $\mathrm{Mg}$ do solo na profundidade de 0-15 cm. Porém, Motta Neto (1995) verificou que a adubação orgânica manteve os teores de Ca e $\mathrm{Mg}$ na camada superficial $(0-3 \mathrm{~cm})$, enquanto nos demais tratamentos ocorreu uma queda na concentração. Holanda et al. (1984) observaram que os teores desses nutrientes no solo aumentaram com a dosagem de esterco.

Os resultados das Figs. 2 e 3 mostram efeitos semelhantes entre a permanência e exportação da parte aérea, com exceção do Ca no Sistema II, caracterizando uma pequena contribuição das plantas na reciclagem de $\mathrm{Ca}$ e $\mathrm{Mg}$, provavelmente devido ao curto período de avaliação. Tais resultados contrariam os obtidos por Testa et al. (1992), em que as sucessões de culturas alteraram os teores de $\mathrm{Ca}$ e Mg na mesma proporção da produção de biomassa.

Na profundidade de 3-9 $\mathrm{cm}$, não se verificaram diferenças no teor de $\mathrm{Ca}$ e $\mathrm{Mg}$ entre os tratamentos, caracterizando, assim, a contribuição superficial desses tratamentos. Os teores de $\mathrm{Ca}$ e $\mathrm{Mg}$ também não foram alterados pelas seqüências de culturas na profundidade de 0-20 cm, em trabalho desenvolvido por Santos et al. (1995).

$\mathrm{O}$ teor de $\mathrm{P}$ na profundidade de $0-3 \mathrm{~cm}$ também foi superior nas parcelas com adubação orgânica (Fig. 3), que, mesmo não diferindo estatisticamente do tratamento com a permanência da parte aérea, foi

TABELA 1. Valores médios de $\mathrm{pH}_{\mathrm{CaCl}}, \mathrm{Al}, \mathrm{H}+\mathrm{Al}, \mathrm{P}, \mathrm{K}, \mathrm{Ca}, \mathrm{Mg}, \mathrm{C}$ orgânico e CTC $\mathrm{pH} 7$ do solo nas duas profundidades e épocas de amostragem envolvendo tratamentos com forrageiras e adubações.

\begin{tabular}{lcccccccccc}
\hline Época & $\begin{array}{c}\text { Prof. } \\
(\mathrm{cm})\end{array}$ & $\begin{array}{c}\mathrm{pH} \\
\left(\mathrm{CaCl}_{2}\right)\end{array}$ & $\begin{array}{c}\mathrm{Al} \\
-\end{array}$ & $\mathrm{H}+\mathrm{Al}$ & $\mathrm{K}$ & $\begin{array}{c}\mathrm{Ca} \\
\left(\mathrm{cmol}_{\mathrm{c}} \mathrm{kg}^{-1}\right)\end{array}$ & $\mathrm{Mg}$ & $\mathrm{CTC}$ & $\begin{array}{c}\mathrm{P} \\
\left(\mathrm{mg} \mathrm{kg}^{-1}\right)\end{array}$ & $\begin{array}{c}\mathrm{C} \text { org. } \\
(\%)\end{array}$ \\
\hline Maio/94 & $0-3$ & 4,9 & 0,31 & 6,32 & 0,42 & 6,20 & 3,14 & 16,78 & 18,50 & 2,65 \\
Maio/94 & $3-9$ & 4,9 & 0,18 & 5,89 & 0,23 & 5,07 & 2,79 & 13,98 & 5,28 & 1,37 \\
Maio/94 & Média & 4,9 & 0,24 & 6,10 & 0,32 & 5,63 & 2,96 & 15,38 & 11,89 & 2,01 \\
Maio/95 & $0-3$ & 5,4 & 0,00 & 5,37 & 0,80 & 8,09 & 4,43 & 18,63 & 38,25 & 3,24 \\
Maio/95 & $3-9$ & 4,9 & 0,15 & 5,85 & 0,27 & 5,43 & 2,98 & 17,78 & 5,64 & 1,46 \\
Maio/95 & Média & 5,1 & 0,07 & 5,61 & 0,53 & 6,76 & 3,70 & 18,20 & 21,94 & 2,35 \\
\hline
\end{tabular}


superior em 23,3 mg kg-1, o que representa do ponto de vista da fertilidade, uma grande variação. Nessa mesma área experimental, Lucchesi (1988) não verificou efeito da adubação orgânica nos teores de P, porém Motta Neto (1995) observou que o teor de $\mathrm{P}$ do solo aumentou com a adição de esterco bovino. Holanda et al. (1984) observaram aumentos lineares de P no solo com as dosagens de esterco. Em função da pequena extração do $P$ pela planta, não se constatou diferença significativa entre a permanência e exportação da parte aérea, apesar de mostrar-se supe-

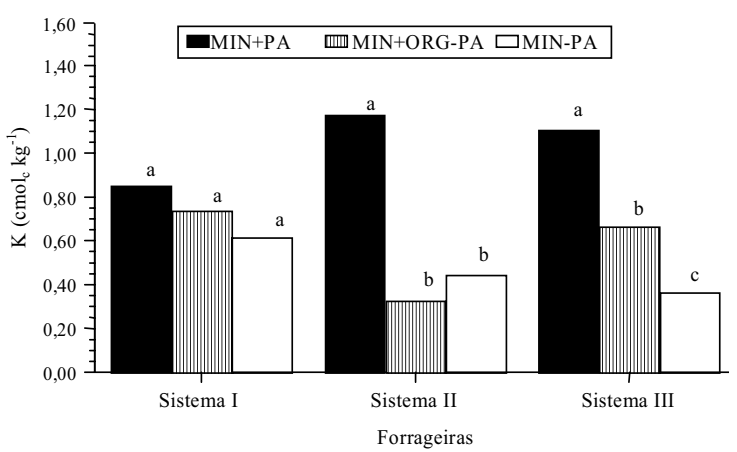

FIG. 1. Efeito das adubações e forrageiras no $\mathrm{K}$ do solo na profundidade de $0-3 \mathrm{~cm}$. Coleta maio/95. (Médias com a mesma letra dentro de cada sistema forrageiro não diferem significativamente pelo teste de Tukey a $5 \%$ de probabilidade).

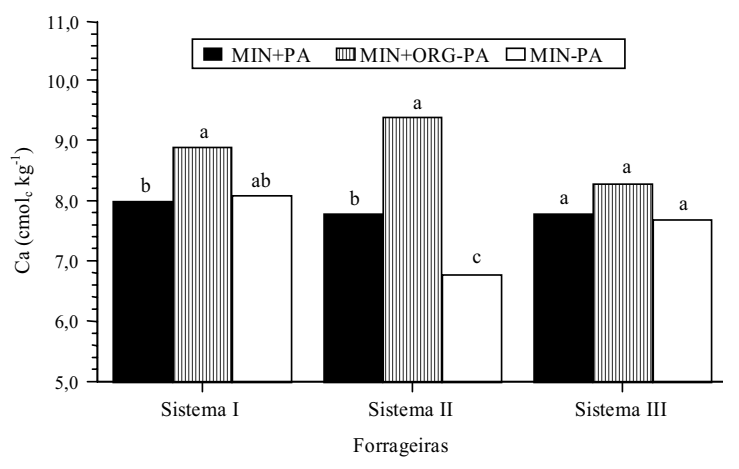

FIG. 2. Efeito das adubações e forrageiras no Ca do solo na profundidade de $0-3 \mathrm{~cm}$. Coleta maio/95. (Médias com a mesma letra dentro de cada sistema forrageiro não diferem significativamente pelo teste de Tukey a $5 \%$ de probabilidade). rior nos tratamentos em que o resíduo vegetal permaneceu sobre a superfície do solo.

$\mathrm{O}$ efeito dos tratamentos não foi identificado na camada de 3-9 cm, isto mostra a pouca mobilidade desse nutriente no perfil, bem como a contribuição superficial da calagem e adubação em cobertura. Os maiores teores de $\mathrm{P}$ observados na camada superficial estão de acordo com resultados obtidos por Sidiras \& Pavan (1985) e Santos et al. (1995).

$\mathrm{O}$ adubo orgânico, além de fornecer nutrientes, aumenta o teor de matéria orgânica do solo, contribuindo na melhoria das características químicas, físicas e biológicas. Nos três sistemas forrageiros, a adição de esterco bovino elevou os teores de $\mathrm{C}$ orgânico na profundidade de 0-3 cm (Fig. 4), demonstrando a importância dessa adubação em áreas onde se pretende elevar os níveis de matéria orgânica do solo. Lucchesi (1988) observou que os teores de C orgânico foram superiores no tratamento com adubação orgânica, em contrapartida, Motta Neto (1995) não verificou diferenças com a adição de esterco bovino. No Sistema III, a diferença entre adubação orgânica e permanência da parte aérea é de 0,6 unidades percentuais o que representa uma grande variação na fertilidade, apesar de esta não ser identificada estatisticamente.

A exportação ou permanência da parte aérea sobre a superfície do solo, da mesma forma que os teores de $\mathrm{Ca}, \mathrm{Mg}$ e $\mathrm{P}$, não modificou estatisticamente os teores de C orgânico; no entanto, observa-se no tra-

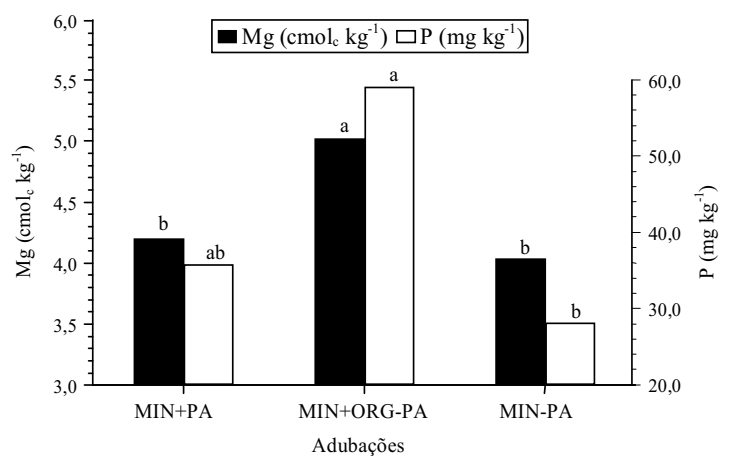

FIG. 3. Efeito das adubações no $\mathrm{Mg}$ e $\mathrm{P}$ do solo na profundidade de 0-3 cm. Coleta maio/95. (Médias com a mesma letra dentro de cada nutriente não diferem significativamente pelo teste de Tukey a $5 \%$ de probabilidade).

Pesq. agropec. bras., Brasília, v.35, n.2, p.289-297, fev. 2000 
tamento com permanência da parte aérea (Fig. 4), teores de C orgânico superiores em relação ao tratamento com exportação. Christensen et al. (1994) observaram, após cinco anos de experimentação, que o teor de C orgânico foi superior no plantio direto, em comparação com o cultivo mínimo, e Sidiras \& Pavan (1985) obtiveram maiores teores de C orgânico no sistema de vegetação permanente, o que mostra a importância dos resíduos vegetais sobre o solo. No tratamento com adubação orgânica, as forrageiras perenes (Sistemas I e II) foram superiores às anuais (Sistema III), mostrando, assim, que o ciclo da cultura teve maior influência que a produção de matéria seca.

Na profundidade de 3-9 cm, os maiores teores de C orgânico foram obtidos no tratamento com adubação orgânica e nas forrageiras dos Sistemas I e II. Nessa profundidade, o Sistema I, apesar de apresentar menor produção de matéria seca, mostrou melhores teores de $\mathrm{C}$ orgânico. $\mathrm{O}$ destaque das forrageiras perenes caracteriza a importância da cobertura do solo e do sistema radicular no processo de recuperação.

Com relação aos teores de $\mathrm{N}$ total (Fig. 5), observa-se um comportamento semelhante ao do C orgânico principalmente na camada superficial. Esse comportamento é esperado, pois, segundo Stevenson (1982), acima de $90 \%$ do $\mathrm{N}$ total encontra-se na forma

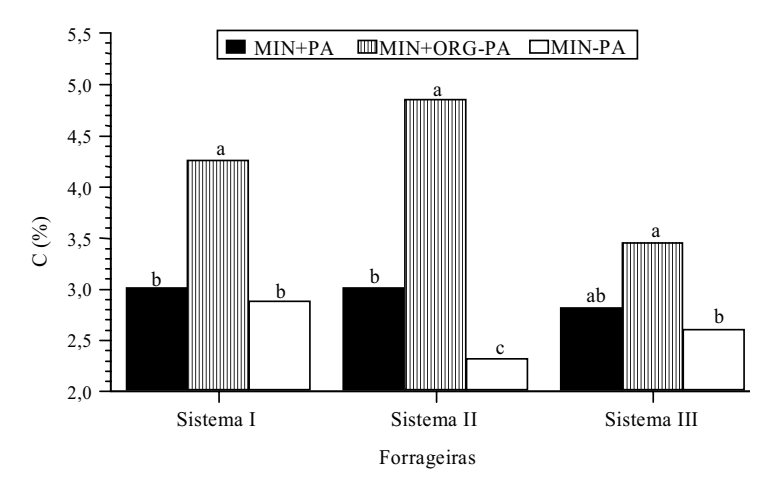

FIG. 4. Efeito das adubações e forrageiras no $\mathrm{C}$ orgânico do solo na profundidade de $0-3 \mathrm{~cm}$. Coleta maio/95. (Médias com a mesma letra dentro de cada sistema forrageiro não diferem significativamente pelo teste de Tukey a $5 \%$ de probabilidade). orgânica. Portanto, o C orgânico e o N total representam a matéria orgânica do solo, a qual apresenta estrutura relativamente estável, caracterizada pela relação $\mathrm{C} / \mathrm{N}$. Neste experimento, a relação $\mathrm{C} / \mathrm{N}$ média do solo na profundidade de $0-3 \mathrm{~cm}$ foi de 11,3 , não apresentando efeito dos tratamentos. Melo (1994), no trabalho desenvolvido com espécies forrageiras em áreas degradadas, encontrou uma relação $\mathrm{C} / \mathrm{N}$ de 12,1. Segundo Tisdale et al. (1993), a relação C/N em solos não degradados e em equilíbrio com o meio ambiente é de 10 a 12.

A CTC pH 7 (Fig. 6) mostrou um comportamento semelhante ao do $\mathrm{C}$ orgânico e ao do $\mathrm{N}$ total, principalmente na camada de $0-3 \mathrm{~cm}$. Testa et al. (1992) também verificaram que o maior efeito das culturas sobre a CTC $\mathrm{pH} 7$ ocorreu na camada superficial de $0-2,5 \mathrm{~cm}$. Os resultados obtidos neste experimento confirmam a importância da matéria orgânica na formação de cargas.

\section{Caracterização da palhada}

$\mathrm{Na}$ Tabela 2, observa-se que a adubação mineral com permanência da parte aérea proporcionou maior quantidade de matéria seca residual em todos os sistemas, comportamento esperado em função do manejo das forrageiras.

$\mathrm{Na}$ avaliação quanto à eficiência da proteção do solo, a cobertura residual é muito importante. Neste

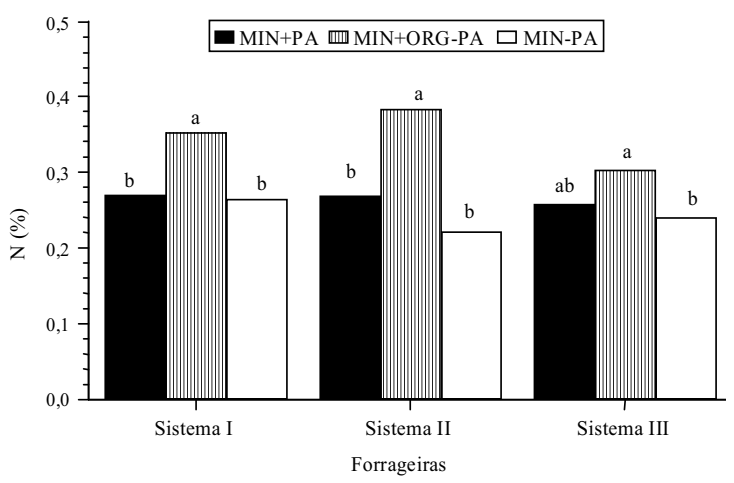

FIG. 5. Efeito das adubações e forrageiras no $\mathbf{N}$ total do solo na profundidade de $\mathbf{0 - 3} \mathrm{cm}$. Coleta maio/95. (Médias com a mesma letra dentro de cada sistema forrageiro não diferem significativamente pelo teste de Tukey a $5 \%$ de probabilidade). 
experimento, observa-se que as espécies perenes (Sistemas I e II) mostraram maior matéria seca residual e maior cobertura do solo, caracterizando uma relação direta entre essas variáveis. Bragagnolo \&

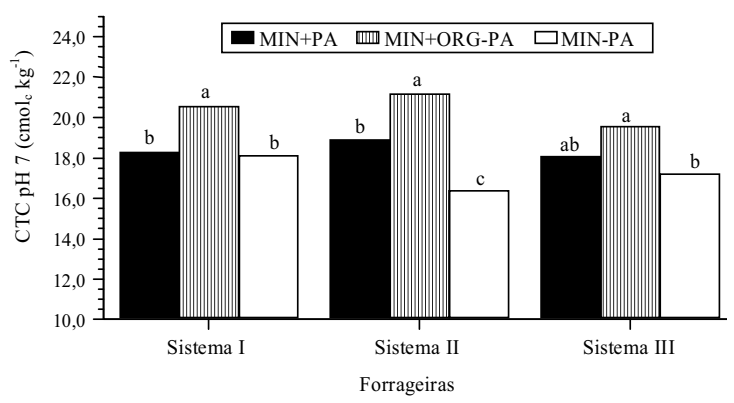

FIG. 6. Efeito das adubações e forrageiras na CTC pH 7 do solo na profundidade de $\mathbf{0 - 3} \mathrm{cm}$. Coleta maio/95. (Médias seguidas da mesma letra dentro de cada sistema forrageiro não diferem significativamente pelo teste de Tukey a $5 \%$ de probabilidade).
Mielniczuk (1990), no entanto, observaram que algumas seqüências de culturas, apesar dos elevados valores de matéria seca residual, apresentaram baixos índices de cobertura do solo, em face da constituição lenhosa do resíduo.

As porcentagens médias de cobertura do solo, em todos os sistemas e adubações, são elevadas, conforme Tabela 2. A menor cobertura do solo verificada neste experimento foi de $82 \%$, considerada adequada, do ponto de vista do controle à erosão. Segundo Tisdale et al. (1993), não existem perdas de solo pelo vento e pela água com cobertura de 70 e $80 \%$, respectivamente, e, de acordo com Bertol et al. (1987), uma cobertura do solo equivalente a $60 \%$ da área promove uma redução de $80 \%$ nas perdas do solo por erosão, em relação ao solo descoberto.

A quantidade de $\mathrm{C}$ e $\mathrm{N}$ sobre o solo na coleta de fevereiro/95 mostrou interação significativa entre adubações e forrageiras, sendo a adubação mineral com permanência da parte aérea superior às demais, com exceção do Sistema III (Tabela 2). Com relação

TABELA 2. Matéria seca residual, cobertura do solo, quantidade de $\mathrm{C}$ e $\mathrm{N}$ sobre o solo e teor de $\mathrm{C}$ orgânico e $\mathrm{N}$ total do solo na profundidade de $0-3 \mathrm{~cm}$ envolvendo tratamentos com adubações e espécies forrageiras ${ }^{1}$.

\begin{tabular}{llccccccc}
\hline Forrageira $^{2}$ & Adubação & $\begin{array}{c}\text { Matéria } \\
\text { seca }^{3}\end{array}$ & $\begin{array}{c}\text { Matéria } \\
\text { seca }^{4}\end{array}$ & $\begin{array}{c}\text { Cobertura } \\
\text { do solo }^{5}\end{array}$ & $\begin{array}{c}\text { C sobre } \\
\text { o solo }\end{array}$ & $\begin{array}{c}\text { N sobre } \\
\text { o solo }\end{array}$ & $\begin{array}{c}\text { C do solo } \\
(0-3 \mathrm{~cm})^{6}\end{array}$ & $\begin{array}{c}\text { N do solo } \\
\left(0-3 \mathrm{~cm}^{6}\right.\end{array}$ \\
\hline Sistema I & MIN+PA & 3.260 & 1.892 & 97 & $789 \mathrm{a}$ & $31 \mathrm{a}$ & $2,97 \mathrm{~b}$ & $0,269 \mathrm{~b}$ \\
Sistema I & MIN+ORG-PA & 828 & 906 & 96 & $365 \mathrm{~b}$ & $16 \mathrm{~b}$ & $4,25 \mathrm{a}$ & $0,352 \mathrm{a}$ \\
Sistema I & MIN-PA & 648 & 499 & 90 & $199 \mathrm{~b}$ & $8 \mathrm{~b}$ & $2,87 \mathrm{~b}$ & $0,264 \mathrm{~b}$ \\
\hline Sistema II & MIN+PA & 3.785 & 3.482 & 100 & $1.503 \mathrm{a}$ & $39 \mathrm{a}$ & $2,98 \mathrm{~b}$ & $0,268 \mathrm{~b}$ \\
Sistema II & MIN+ORG-PA & 1.472 & 680 & 97 & $277 \mathrm{~b}$ & $10 \mathrm{~b}$ & $4,85 \mathrm{a}$ & $0,383 \mathrm{a}$ \\
Sistema II & MIN-PA & 1.049 & 827 & 90 & $341 \mathrm{~b}$ & $9 \mathrm{~b}$ & $2,31 \mathrm{c}$ & $0,221 \mathrm{~b}$ \\
\hline Sistema III & MIN+PA & 3.153 & 538 & 92 & $217 \mathrm{a}$ & $8 \mathrm{a}$ & $2,82 \mathrm{ab}$ & $0,257 \mathrm{ab}$ \\
Sistema III & MIN+ORG-PA & 508 & 393 & 82 & $163 \mathrm{a}$ & $6 \mathrm{a}$ & $3,44 \mathrm{a}$ & $0,303 \mathrm{a}$ \\
Sistema III & MIN-PA & 727 & 291 & 86 & $119 \mathrm{a}$ & $4 \mathrm{a}$ & $2,60 \mathrm{~b}$ & $0,239 \mathrm{~b}$ \\
\hline
\end{tabular}

${ }^{1}$ Médias seguidas da mesma letra dentro de cada sistema forrageiro não diferem significativamente pelo teste de Tukey a $5 \%$ de probabilidade;

2 Sistema I - gramíneas e leguminosas perenes (pensacola, trevo-branco, trevo-vermelho e cornichão); Sistema II - gramíneas e leguminosas perenes (hemártria, trevo-branco, trevo-vermelho e cornichão); Sistema III - gramíneas e leguminosas anuais (azevém, ervilhaca-peluda e trevo-vesiculoso, no inverno; sorgo e crotalária no verão).

3 Coleta outubro/94;

${ }^{4}$ Coleta fevereiro/95;

5 Média do período (maio/94 a maio/95);

${ }^{6}$ Coleta maio/95. 
às forrageiras, verifica-se uma superioridade das espécies perenes, apesar de mostrar significância somente no tratamento com permanência da parte aérea.

Na Tabela 2 observa-se que os teores de C orgânico e $\mathrm{N}$ total do solo são maiores no tratamento com adubação orgânica, conforme discutido anteriormente nas Figs. 4 e 5, o que mostra maior efeito desta em relação à quantidade de $\mathrm{C}$ e $\mathrm{N}$ sobre o solo. O teste de correlação entre teor no solo e quantidade sobre o solo não apresentou significância estatística a $5 \%$ de probabilidade. No entanto, se observar somente os tratamentos sem adubação orgânica, verifica-se que as parcelas com maior quantidade de $\mathrm{C}$ e $\mathrm{N}$ sobre o solo apresentam maior teor no solo. Testa et al. (1992) observaram uma relação direta entre $\mathrm{C}$ sobre o solo e teor de $\mathrm{C}$ do solo, onde as maiores adições de $\mathrm{C}$ na superfície refletiram em maiores teores de $\mathrm{C}$ no perfil do solo. Franzluebbers et al. (1995) constataram que na profundidade de 0-5 cm o teor de C orgânico foi superior no sistema de rotação, comparado ao monocultivo, devido à maior entrada de $\mathrm{C}$ via resíduo e raízes das culturas. Nessa profundidade, os autores também obtiveram teores de $\mathrm{C}$ orgânico superiores no sistema de plantio direto, comparado com o preparo convencional.

\section{CONCLUSÕES}

1. As adubações e as espécies forrageiras propiciam alterações nas características químicas do solo, porém não alteram $\mathrm{pH}_{\mathrm{CaCl}_{2}}, \mathrm{Al} \mathrm{e} \mathrm{H}+\mathrm{Al}$, nas duas profundidades, bem como o $\mathrm{P}, \mathrm{Ca}$ e $\mathrm{Mg}$ na camada de $3-9 \mathrm{~cm}$.

2. A adubação orgânica propicia melhores teores de $\mathrm{P}, \mathrm{Ca}$ e $\mathrm{Mg}$ na camada de $0-3 \mathrm{~cm}$ e de $\mathrm{C}$ orgânico, $\mathrm{N}$ total e CTC pH 7 nas duas camadas.

3. A permanência da parte aérea apresenta melhores resultados, em relação à adubação orgânica, no teor de $\mathrm{K}$ do solo.

4. Todos os nutrientes do solo são presentes em menor quantidade quando se faz a adubação mineral com exportação da parte aérea.

5. As espécies perenes são mais adequadas para a recuperação das áreas degradadas.

6. A quantidade de $\mathrm{C}$ e $\mathrm{N}$ presente no material vegetal morto sobre o solo tem menor efeito que a adubação orgânica nos teores de $\mathrm{C}$ orgânico e N total do solo, na profundidade de $0-3 \mathrm{~cm}$.

7. As porcentagens médias de cobertura do solo em todos os sistemas forrageiros são adequadas sob o ponto de vista do controle da erosão.

\section{REFERÊNCIAS}

BERTOL, I.; COGO, N.P.; LEVIEN, R. Relações de erosão hídrica com métodos de preparo do solo, na ausência e na presença de cobertura por resíduo cultural de trigo. Revista Brasileira de Ciência do Solo, Campinas, v.11, p.187-192, 1987.

BHAT, A.K.; BERI, V.; SIDHU, B.S. Effect of long-term recycling of crop residues on soil productivity. Indian Society of Soil Science Journal, New Delhi, v.39, n.2, p.380-382, 1991.

BRAGAGNOLO, N.; MIELNICZUK, J. Cobertura do solo por resíduos de oito seqüências de culturas e seu relacionamento com a temperatura e umidade do solo, germinação e crescimento inicial do milho. Revista Brasileira de Ciência do Solo, Campinas, v.4, p.91-98, 1990.

CHRISTENSEN， N.B.; LINDEMANN， W.C.; SALAZAR-SOSA, E.; GILL, L.R. Nitrogens and carbon dynamics in no-till an stuble mulch. Agronomy Journal, Madison, v.86, p.298-303, 1994.

COSTA, J.M.V. da; GARDNER, A.L. Sistema botanal 2: manual do usuário. Brasília : EmbrapaDMQ, 1984. 27p. (Embrapa-DMQ. Documento, 12).

FAGERIA, N.K.; BALIGAR, V.C.; JONES, C.A. Growth and mineral nutrition of field crops. New York : M. Dekker, 1991. 476p.

FAVARETTO, N.; MORAES, A. de; MOTTA, A.C.V.; PREVEDELLO, B.M.S. Efeito da revegetação e da adubação de área degradada na produção de matéria seca e na absorção de nutrientes. Pesquisa Agropecuária Brasileira, Brasília, v.35, n.2, p.299-306, fev. 2000.

FRANZLUEBBERS, A.J.; HONS, F.M.; ZUBERER, D.A. Soil organic carbon, microbial biomass and mineralizable carbon and nitrogen in sorghum. Soil Science Society of America. Journal, Madison, v.59, p.460-466, 1995. 
HAVLIN, J.L.; KISSEL, D.E.; MADUX, L.D.; CLAASSEN, M.M.; LONG, J.H. Crop rotation and tillage effects organic carbon and nitrogen. Soil Science Society of America. Journal, Madison, v.54, p.448-452, 1990.

HILDEBRAND, C. Manual de análise química de solos e plantas. Curitiba : UFPR, 1977. 225p.

HOLANDA, J.S.; TORRES FILHO, J.; BEZERRA NETO, F. Alterações na fertilidade de dois solos adubados com esterco de curral e cultivados com caupi. Revista Brasileira de Ciência do Solo, Campinas, v.8, p.301-304, 1984.

KLEPKER, D.; ANGHINONI, I. Características físicas e químicas do solo afetadas por métodos de preparo e modos de adubação. Revista Brasileira de Ciência do Solo, Campinas, v.19, p.359-401, 1995.

LUCCHESI, L.A.C. Influência de sucessões de culturas forrageiras e adubações sobre a recuperação de um solo degradado pela mineração do xisto e sobre sua mesofauna edáfica (Acari e Collembola). Curitiba : UFPR, 1988. 252p. Dissertação de Mestrado.

MEDEIROS, J.C.; MIELNICZUK, J.; PEDO, F. Sistemas de culturas adaptadas à produtividade, recuperação e conservação do solo. Revista Brasileira de Ciência do Solo, Campinas, v.11, p.199-204, 1987.

MELO, E.F.R.Q. Recuperação de área degradada da Itaipu Binacional com forrageiras e adubações. Foz do Iguaçu : CNPq/Itaipu Binacional, 1994. 159p.

MOTTA NETO, J.A. Avaliação do uso de forrageiras e de adubações na recuperação de propriedades químicas e físicas de um solo degradado pela mineração do xisto. Curitiba : UFPR, 1995. 83p. Dissertação de Mestrado.

PAVAN, M.A.; BLOCH, M. de F.; ZEMPULSKI, H. da C.; MIYAZAWA, M.; ZOCOLER, D.C. Manual de análise química de solo e controle de qualidade. Londrina : IAPAR, 1992. 39p. (Circular, 76).

SANTOS, H.P. dos; TOMM, G.O.; LHAMBY, J.C.B. Plantio direto versus convencional: efeito na fertilidade do solo e no rendimento de grãos de culturas em rotação com cevada. Revista Brasileira de Ciência do Solo, Campinas, v. 19, p.449-454, 1995.

SIDIRAS, N.; PAVAN, M.A. Influência do sistema de manejo do solo no seu nível de fertilidade. Revista Brasileira de Ciência do Solo, Campinas, v.9, p.249-254, 1985.

STEVEnSON, F.J. Humus chemistry: genesis, composition reactions. New York : J. Wiley, 1982. $443 p$.

TEDESCO, M.J.; WOLKWEISS, S.J.; BOHNEM, H. Análises de solo, plantas e outros materiais. Porto Alegre : UFRGS, 1985. 188p. (Boletim técnico, 5).

TERABE, K. Programa de reabilitação das áreas degradadas pela mineração do xisto Petrobrás-Six. In: SIMPÓSIO NACIONAL SOBRE RECUPERAÇÃO DE ÁREAS DEGRADADAS, 1., 1992, Curitiba. Anais. Curitiba : UFPR/FUPEF, 1992. p.458-461.

TESTA, V.M.; TEIXEIRA, L.A.J.; MIELNICZUK, J. Características químicas de um Podzólico VermelhoEscuro afetadas por sistemas de culturas. Revista Brasileira de Ciência do Solo, Campinas, v.16, p.107-114, 1992.

TISDALE, S.L.; NELSON, W.L.; BEATON, J.D.; HAVLIN, J.L. Soil fertility and fertilizers. 5.ed. New York : MacMillan, 1993. 635p.

TROEH, F.R.; HOBBS, J.A.; DONAHUE, R.L. Soil and water conservation for productivity and environmental protection. Englewood Cliffs : Prentice-Hall, 1980. 718p. 